\title{
Fundamental Building Technology
}

\author{
Andrew J. Charlett \\ Taylor \& Francis, Abingdon, UK; 2007: ISBN 978-0-415-38624-1; 288pp; £19.99; \\ paperback
}

Journal of Building Appraisal (2009) 4, 233-234. doi:10.1057/jba.2008.35

Another book on construction? This offering sets out to provide guidance to understand the functional requirements of each part of a building and takes the house as a basic building model. Aimed at students it provides Self-Assessment Questions throughout, with answers posted on a freely accessible website. Any new book on construction is up against formidable competition, namely Mitchell's and McKay's and the BRE Building Element Series.

The first chapter sets out the basic necessities for a 'shelter' and describes the elements needed to build an enclosure. Functional requirements then follow and include strength and stability, weather resistance, fire resistance, thermal and sound insulation, durability, appearance and quality. A passing reference is given to a British Standard for fire tests, although it would be more useful at this early stage to introduce the student to the mandatory requirements of Building Regulations, Approved Documents and BS Codes of Practice.

The next chapter covers site investigation and the type of ground with a detailed description of site and laboratory tests. Chemical analysis for sulphates is recommended, although there is no explanation of problems that can occur when building on contaminated land. The third chapter introduces excavation, including setting out the building, type of plant available for both trench and bulk excavation, and methods of support for various soils. Subsequent chapters deal with the foundation through to the roof.

Comprehensive cover is given to foundation types, including strip footings, raft slab and short bored piles, and useful drawings cover the build-up of the items. The effect of trees on foundations provides a timely warning of problems that can arise from the proximity of existing trees and the care needed when planting new ones.

Concrete is the subject of a separate chapter and deals with the variety of cements available, aggregates and mix design, but omits the requirements for testing. The sixth chapter deals with the single-storey basement and relies heavily on a British Standard recognised to be out of date. No mention is made of the work and publications of the Basement Development Group or its Approved Document. In the reviewers experience minimal use will be found of asphalt tanking or waterstops in concrete retaining walls in house construction.

Bricks and blocks are dealt with in the following chapter, covering sourcing clay and aggregates for their manufacture, the properties that are obtained and the designation in British Standards. Mortars would have logically followed in the same chapter, but the reader will have to wait until two chapters later.

External walls follow in Chapter 8, with headings of strength and stability, weather resistance, sound and thermal insulation, fire resistance, durability and appearance. No reference is made of guidelines in Building Regulations Approved Document Part $\mathrm{C}$ on what wall construction can be used in a particular exposure zone, fundamental to avoiding damp penetration problems. More on walling is given in the next chapter, with several pages on brick bonding, perhaps relevant to older houses. However, most houses these days have brickwork in stretcher bond. This section ends with data on lintels, window and door reveals and cills. 
The next chapter returns to the fundamentals of a material, wood. It deals comprehensively with wood growth, conversion, rots, insect attack and sheet materials of wood-based origin. Ground floors are discussed next, covering solid, suspended timber and beam and block construction, followed by upper floor construction with details on timber construction. The author dismisses concrete floors with the view that they are not popular; the industry seems to think otherwise.

The next element covered is flat roofing, its structure, insulation and the covering. There is a useful section on interstitial condensation, although a reference to calculation packages would have been useful. Cold deck designs are described, but there is no mention that they are effectively prohibited in Scotland. Roof coverings detail mastic asphalt, bituminous felts and sheet metal. There is no mention of single ply or other modern materials.

A pitched roof structure covers both site cut and trussed rafter constructions and ventilation requirements. The roof coverings detailed include slates, clay and concrete tiles, and reference to flashings at abutments.

The final chapter (dealing with elements) introduces timber and steel frame housing, now known as MMC (Modern Methods of Construction). Brief coverage is given, but it would have been useful to refer to other publications that give more details. Policy makers inform us that much more housing will have to be built using these methods if the required house completion numbers are to be met.

The next part of the book introduce components, windows, the materials used for both framing and glazing and the methods for fixing but not the more usual cavity closer. Doors are also discussed, concluding with hinges, locks and self-closing devices. Stairs follow with design, including the requirements for risers and the going. No mention is made of pre-cast concrete units.

The concluding chapters cover plaster and plasterboards, internal walls and partitions, internal finishes and external wall finishes. A lengthy glossary and bibliography complete the publication.

It is surprising to find that there are no chapters on services or even a mention of the impact they have on the structure. The days of the outside tap and privy are long gone and there are ever-increasing demands on services. Pipe runs for drainage, water supply and heating need careful planning as do cable installations. Another drawback is the lack of adequate references throughout the book. Some British Standards are referred to within the text but the long list at the back of the book is just in numerical order, which is of no help in looking for a specific topic. The case is similar with the list of BRE Digests, which is also in numerical order and does not include the Good Building Guide series that offer the more practical help that a student will need. Fortunately, our computer-literate student will soon locate appropriate websites that provide good search facilities.

This book has a rather an old-fashioned approach to its subject and is deficient in some areas, with the omission of any reference to services incomprehensible. For a student looking for possible exam questions the text will be of help, and the website is the location for the model answers.

Peter Trotman BRE Associate 